\title{
Experimental Methods for Selecting Base Isolation Parameters for Public Buildings
}

\author{
Y. Ribakov* and I. Iskhakov
}

Department of Civil Engineering, Ariel University Center of Samaria, Ariel, Israel

\begin{abstract}
As a rule, public buildings should have higher safety level compared to residential ones. Hence, using base isolation systems is an effective and widely known way for improving dynamic response of such buildings. The idea of base isolation was known hundreds years ago, however practical implementation of base isolators started in the last few decades. The main advantage of a base isolation system is that no elements should be added to an isolated building, which is especially important for heritage architecture, forming a part of public buildings. Traditional base isolation system is obtained by using two main base isolator types - elastomeric bearings or friction pendulums. Hundreds of buildings all over the world are provided by such isolators and proved enhanced dynamic behavior. Design of base isolation systems and selection of their properties usually depend on dynamic characteristics of the isolated building. The last can be obtained, for example, by non-destructive impulse testing of the structure before its protection. An appropriate method for structural dynamic parameters experimental estimation was developed by the authors. For this reason an impulse test was carried out on a three-story structural part of a building designed for a seismic region. Another method, which is also discussed in the paper, is based on seismic monitoring of a building in a waiting regime. In some cases the displacements at the base isolation level are rather big and exceed the allowed limits. In such cases it is recommended to add dampers to the base isolation system. Effective variable friction dampers were proposed and tested by the authors. These dampers significantly reduce the displacements between the first floor column and foundation and additionally yield further improvement in the structural seismic response.
\end{abstract}

\section{INTRODUCTION}

Base isolation is one of the significant developments in earthquake engineering in the past decades. It provides protection of building structural elements as well as nonstructural components and yields enhanced seismic response of a whole building (Kelly 1997) [1]. Conventionally designed buildings are supported directly on its foundations, and generally have fixed-base. When base isolation is used, special bearings are installed between the bottom of the building and its foundation. The bearings are flexible in the horizontal direction and reduce the natural frequency of a building. The first dynamic mode of the isolated structure involves deformation only in the isolation system, and the structure above remains almost rigid (Kelly EERCN 1991) [2]. The higher modes' energy is not transmitted through the isolators because they are orthogonal to the first one. Base isolators also add artificial damping to a structure. As a result, the base isolated building's earthquake response becomes not so strong like that of a fixed-base one.

Classic well known base isolation systems are usually obtained by using two main base isolator types - elastomeric bearings (Fig. 1) or friction pendulums (Fig. 2). The properties of these isolators were studied experimentally and theoretically by many researchers during the last decades (Mokha JSEASCE 1990) [3], (Mokha JSEASCE 1991) [4], Naeim 1999) [5], etc.

*Address correspondence to this author at the Department of Civil Engineering, Ariel University Center of Samaria, Ariel, Israel; Tel: +972 546 431 385; Fax: +972 390663 51; E-mail: ribakov@ ariel.ac.il

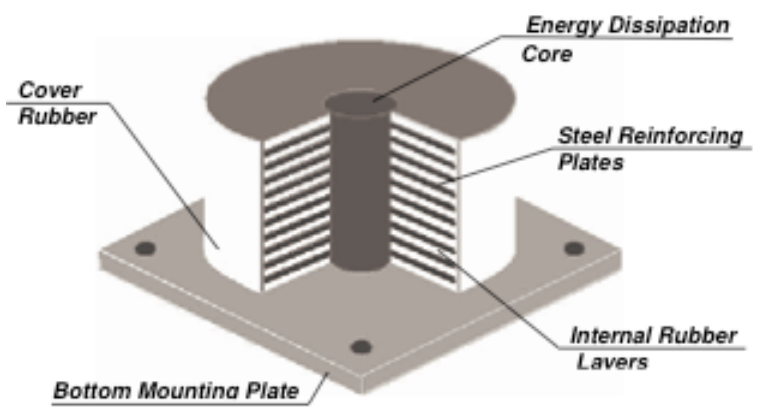

Fig. (1). Elastomeric bearings.

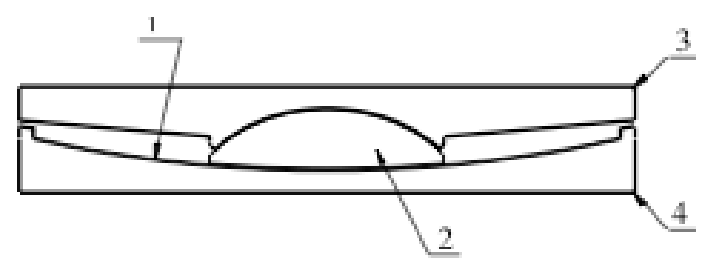

Fig. (2). Friction pendulum scheme: 1- stainless steel concave surface, 2 - articulating slider, 3 - housing plate, 4 - concave plate.

As it can be followed from Fig. (1), elastomeric bearing is a sandwich obtained by alternating layers of steel and rubber, which are vulcanized in order to form a single integrated unit. According to Fig. (2), a friction pendulum consists of a concave plate, articulating slider and housing plate. Both types of isolators are able to displace horizontally in any direction from the center depending on the seismic excitation's direction. 
The most important advantage of using base isolation systems for seismic protection of public buildings is that the retrofitting works are performed at the basement level. It prevents closing the building during the retrofitting period and yields no changes in the structural system saving its historic value. An additional benefit of base isolation systems is their relatively low cost compared to other known solutions.

This paper is focused on review of using base isolation systems in public buildings; non-destructive testing for measuring structural dynamic parameters; using variable friction dampers for reducing displacements at the base isolators level.

\section{OVERVIEW OF BASE ISOLATED PUBLIC BUILD- INGS}

\section{Oakland City Hall}

The building was constructed in 1914 as the first highrise government office in the United States. The building suffered severe damage in the 1989 Loma Prieta erthquake and was immediately closed to occupancy. After the earthquake about $20 \%$ of the buildings lateral bearing capacity was lost in the north-south direction and about $30 \%$ in the east-west one. Extensive cracking of the structural elements appeared.

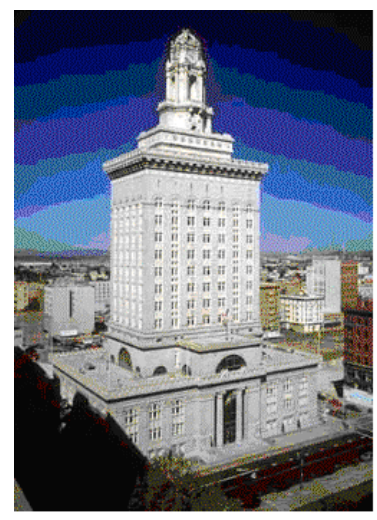

Fig. (3). Base isolated Oakland City Hall.

It was decided to retrofit the structure using a base isolation system. The main aim was to restore the building and to increase its seismic resistance, so that future earthquakes would not cause similar damage. The building is one of the tallest base-isolated structures in the world. It has a complete steel frame. The floors and roofs are made of reinforced concrete slabs supported on the frame. The foundation system is a reinforced concrete plate over the entire basement area. 112 isolators were installed in the basement.

\section{San Francisco City Hall}

The San Francisco's Old City Hall (Fig. 4a) was constructed in the end of the XIX century. During the 1906 earthquake the building was totally damaged, only the dome remained intact. It was finally rebuilt in 1915 (Fig. 4b). During the 1989 Loma Prieta earthquake the City Hall was again subjected to strong seismic excitation. The dome twisted on its steel frame, cracks occurred in the walls and concrete floor slabs at all levels (Internet resource) [6]. The building was not in danger of collapse, but, according to experts' opinion, its seismic resistance was not enough to withstand the next strong earthquake.

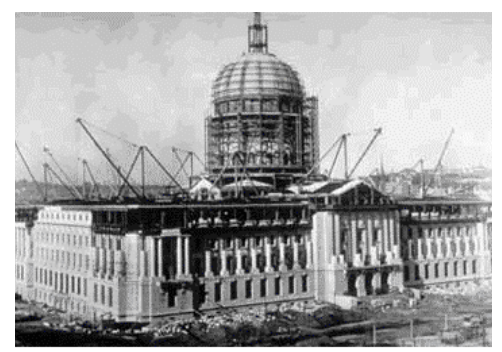

(a)

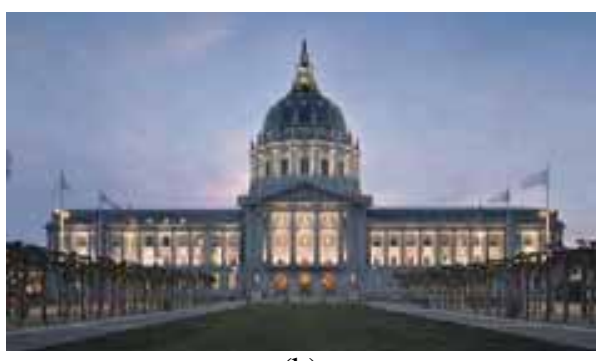

(b)

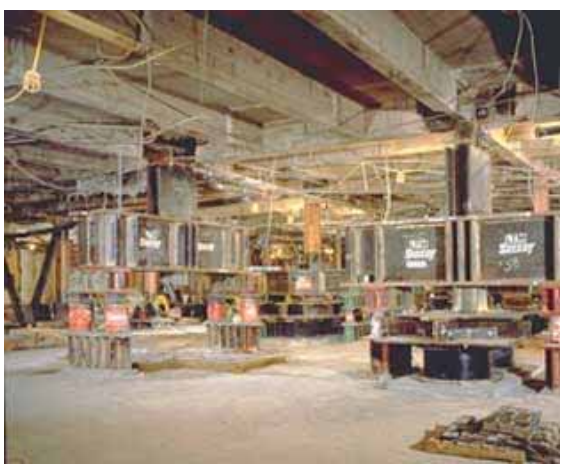

(c)

Fig. (4). San Francisco City Hall: (a) before reconstruction, (b) modern view, (c) installing isolators under the columns.

The building was isolated from its foundation and put on 530 bearings, which were designed to dissipate earthquake energy and allow the building to move horizontally up to 65 $\mathrm{cm}$ without shaking (Fig. 4c).

\section{Base Isolation of Historic Buildings in New Zeeland}

One of New Zealand's most well known landmark buildings has undergone a complete seismic renovation (Internet resource No. 4). The Parliament Buildings (Fig. 5a) are originally built in the 1900's and located approximately 400 meters from one of the regions major fault lines. Over 400 base isolation elastomeric rubber bearings were installed between the structure and its foundation. The isolators allow the building to move horizontally about $40 \mathrm{~cm}$ in an earthquake.

The Old Bank of New Zeeland (Fig. 5b) was reconstructed and provided by base isolation system. This process involved tying of four historic buildings together to create an 
integrated retail and office development (Internet resource) [7].

The Museum of New Zealand (Fig. 5c) is the largest in the Southern Hemisphere base isolated structure weighting about 64000 ton. The base isolation system allows the building to move horizontally up to $50 \mathrm{~cm}$. The isolated building is designed to withstand an earthquake with a 7.5 Richter scale magnitude.

\section{EXPERIMENTAL METHODS FOR ESTIMATION OF BUILDINGS' DYNAMIC PARAMETERS REQUIRED FOR DESIGN OF BASE ISOLATION}

Selection of base isolation parameters directly depends on the structural dynamic characteristics. Known theoretical methods cannot be used for calculation of these characteristics because of the following reasons:

- the materials properties, elements masses and static schemes for existing buildings are not known exactly;

- the hysteretic properties of the materials are usually unknown too;

- it is difficult to take into account in numerical models all the damages, caused to the building during its operation.

It should be mentioned that not all existing experimental methods for estimation of structural dynamic parameters may be applied without limitations, because some of these methods may cause additional damage to the buildings. Hence suitable experimental methods should be selected for this reason. For example, shaking table experiments, which are widely used for investigating structural response of base isolated building models, cannot be used for full-scale structures.

One of the suitable methods for dynamic testing of existing buildings is micro-seismic excitation. In this case a low power underground blast is carried out at a certain distance from the building. The blast load capacity and the distance from the structure are calculated so that inelastic structural behavior is avoided. This method was proved to be especially effective for buildings with distributed masses and structural irregularities (Negmatullaev ICMADSRS 2005) [8].

Another way to apply vibrations to a building is to use a vibration machine. Putting the machine at the basement level can prevent local damages in the structural elements that may be caused if it would be located on the roof or at a story level. The parameters and the regime of the machine are regulated to yield only linear structural vibrations (Iskhakov CDRCSSR 1983) [9].

If the building is located in a region with high seismic activity, it is possible to provide it with seismometers working in a waiting regime. The seismometers may be tuned so that they will be activated when even a low-magnitude earthquake will occur. This method was used for the first time for dynamic testing of RC shells with steel diaphragms in Dushanbe, Tajikistan (Iskhakov CDRCSSR 1983) [9].

For framed buildings with relatively low height and rather high flexibility impulse testing method developed by the authors (Iskhakov EEEJ 2005) [10] may be used. The

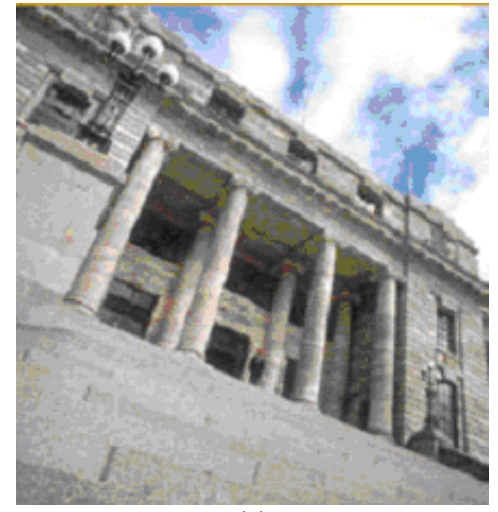

(a)

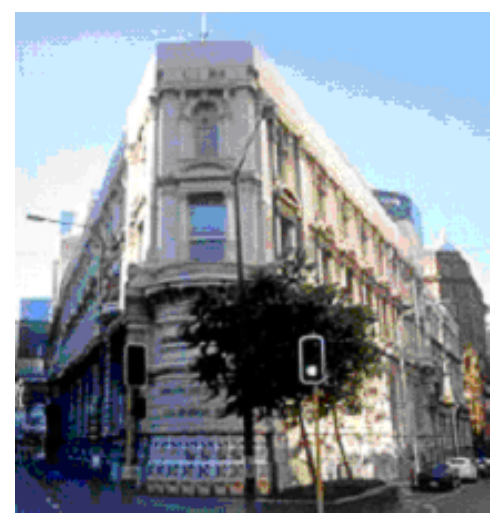

(b)

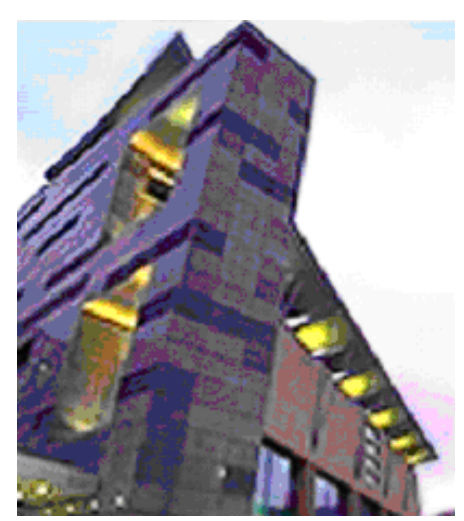

(c)

Fig. (5). Base isolated structures in New Zeeland: (a) Parliament building, (b) Old bank in Wellington, (c) the Museum of New Zealand.

method was also applied for framed shell structures (Iskhakov CDRCSSR 1983) [9].

\section{Impulse Tests}

Impulse tests are usually carried out on framed buildings. For example, tests, performed on a building part consisted of two columns (each column had three floors high) and three slabs were described by the authors in the previous work (Iskhakov EEEJ 2005) [10]. The columns were fixed in sockets in a $30-\mathrm{cm}$ thick raft foundation. Each of the slabs was constructed of two pre-cast over-column plates and a between-column plate $16 \mathrm{~cm}$ thick (Fig. 6). The overall dimensions of the part were $3 \times 9 \mathrm{~m}$, the height of each story being $3 \mathrm{~m}$. 
Dynamical impulse loads were applied to the columnslab joint at the roof level in the plane of the frame. The impulse was applied by instantaneous application of the load by means of a guy cable (Fig. 7) which included a bar, made of high-strength steel. The forces were controlled by rupture of a steel bar and were equal to the required impulse load. Under the impulse load, the tested frame got free vibrations. A steel cable and a hook were installed across the top of the third-floor column. The cable included a wire for pulling the frame. One end of the wire was tied to the hook and the other end to a bulldozer, which tensioned the wire until its failure.

In order to obtain the dynamical parameters of the structure, two accelerometers were located horizontally in the plane of the investigated frame at each floor, and also on the ground. The accelerometers were calibrated and tuned using a laboratory shaking table prior to the start of the tests. The bars were also subjected to preliminary testing in the laboratory in order to measure their absolute deformation under the rupture forces. These measured deformations corresponded to the maximum displacements of the building's roof story under the impulse loads applied.
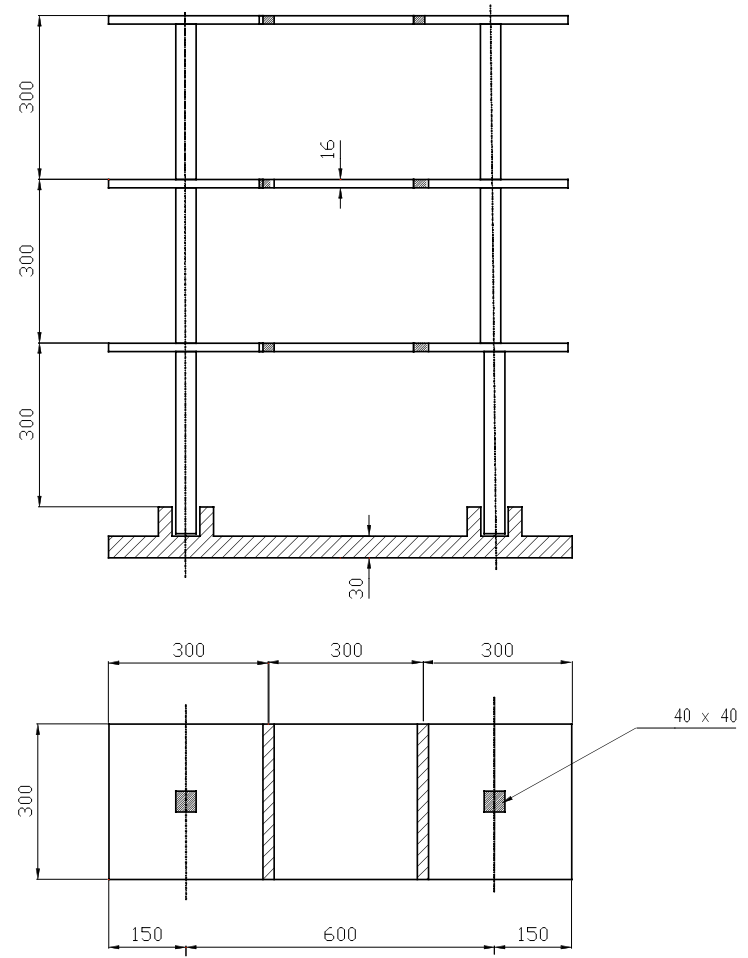

Fig. (6). Structural scheme of tested part (Iskhakov EEEJ 2005) [10].

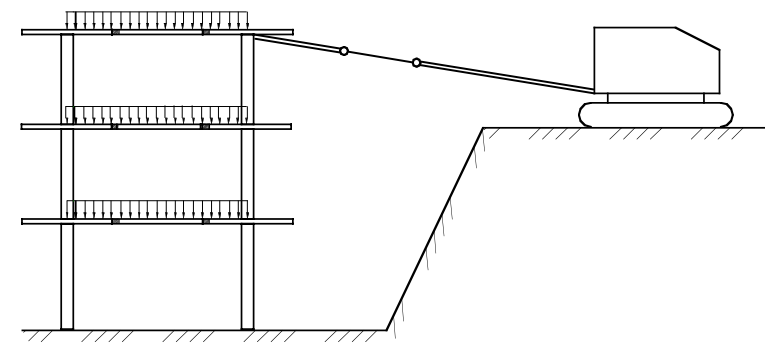

Fig. (7). Application of impulse to building part (Iskhakov EEEJ 2005) [10].
In order to obtain the dynamic parameters of the building, the acceleration records were analyzed using MATLAB software. The natural periods were determined by computation of a frequency response curve showing the resonant peak corresponding to each natural frequency of the structure (Iskhakov EEEJ 2005) [10]. From these data the real damping ratio of the first vibration mode was determined using a logarithmic decrement.

In the above described tests the bars section area was selected to vary the impulse forces applied to the structure. This approach may be also used in testing heritage buildings in order to avoid any damage to its elements. It should be noted that the impulse force magnitude should be enough to yield structural vibrations required to obtain the buildings dynamic parameters.

\section{Vibration Machine Tests}

A dynamic test, using a vibration machine, was reported by the authors earlier (Iskhakov SDTSBJ 2005) [11]. The test was carried out on an 11-story full-scale RC framed building with shear walls (Fig. 8). The building's vibrations were recorded in two regimes: free vibrations and resonance excitations. Changing the unbalanced masses of the vibration machine, different excitation levels were achieved. After each stage natural vibration frequencies of the building were obtained in order to reveal possible damages in the structural elements.

The tests were aimed also to analyze the pre-cast building's state and its joints behavior, influence of shear walls and braces on the dynamic response and to determine the building's dynamic reserves in the linear and nonlinear stages. The PGA of the experimentally applied to the structure vibration loads has been selected according to the code requirements to the seismic zone, in which the building was constructed. For recording of the building's dynamic parameters 11 accelerometers were used. The free vibration test, carried out at the initial stage to obtain the natural vibration periods of the building, was by applying a $1 \times 1 \times 1.5 \mathrm{~m}$ concrete block impact at the upper floor.

Based on the test results, an idea of constructing a structure in seismic zones with higher seismic activity compared to that, for which it has been designed, was examined (Iskhakov SDTSBJ 2005) [11]. In order to select the vibration period of a base isolated structure, a parametric study has been performed. It was shown, that increasing the natural vibration period of a building about twice adapts it to seismic zones with doubled peak ground acceleration, keeping the structural peak response in the same limits.

\section{Waiting Regime Seismic Tests}

All the above mentioned methods for estimation of structural dynamic parameters cannot provide real structural response to natural earthquakes. On the other hand, there is no exact prediction, when the next earthquake will occur. Hence for high importance buildings in this case a seismometric station is equipped. It may be located inside or outside the building. The station includes equipment for initiation of apparatus for measuring of ground and structural displacements, velocities and accelerations during an earthquake. The measuring equipment works in a waiting regime and can 
be tuned to various levels of peak displacements, velocities and accelerations.
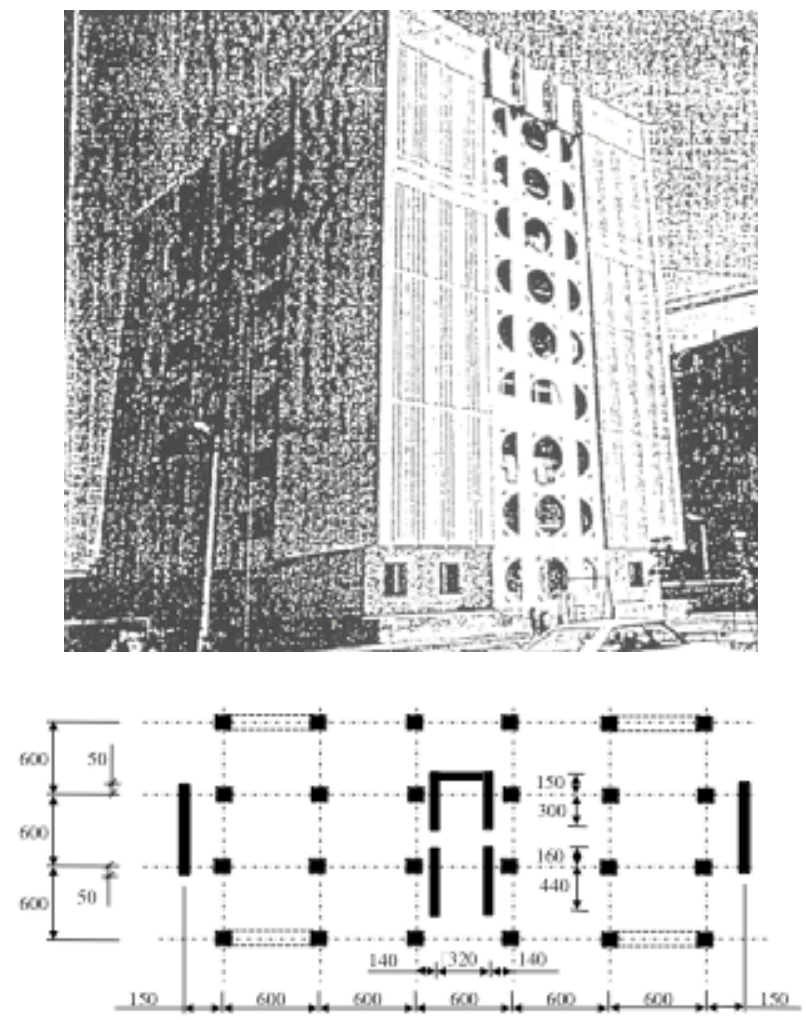

Fig. (8). The investigated building (Iskhakov SDTSBJ 2005) [11].

As to our knowledge, this technique was used for monitoring of dams in seismic zones. It was adapted for investigation of full scale reinforced concrete long-span shells subjected to seismic loads (Iskhakov 1983) [9]. In this study a $24 \times 24 \mathrm{~m} \mathrm{RC}$ roof shell on columns was investigated (Iskhakov BIASSSS 1981) [12]. Records of "ground - column RC shell" system oscillations under strong earthquakes like Gazli, Uzbekistan (18.06.1976) and Isfara, Tajikistan (31.01.1977) were obtained using the waiting regime method. Fragments of ground and shell vertical displacement time histories under the first earthquake are shown in Fig. 9. As it can be followed from this figure, although the ground displacements were chaotic, the shell oscillations had almost a harmonic form.

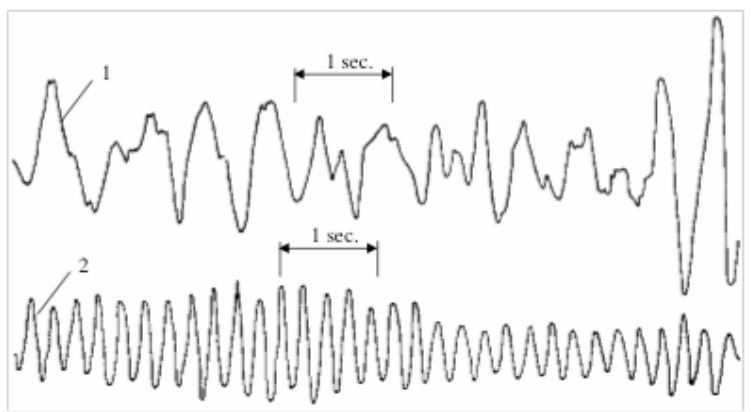

Fig. (9). Ground and shell vertical displacements under the Gazli (1976) earthquake: 1 - ground, 2 - center of the shell (Iskhakov BIASSSS 1981) [12].
The waiting regime method may be applied to various types of buildings. On the one hand, the method is relatively expensive and requires an undefined waiting time period before the strong earthquake will come. But, on the other hand, it provides records of real structural response to natural seismic motions.

\section{USING DAMPERS IN BASE ISOLATION SYSTEMS}

As it was mentioned above, base isolation systems significantly reduce inter-story drifts, seismic forces and inelastic deformations in structural elements, preventing damages that may be caused to a building during an earthquake. This issue is especially relevant for public structures because of their high importance. However, in some cases the positive effect of the base isolation is still not enough. Moreover, using base isolation systems yields relatively big displacements at the isolators' level, which is not always desired.

Addition of dampers to base isolation systems yields further improvement in structural response to earthquakes and decreases the displacements at the isolators (Naeim 1999) [5]. Passive fluid viscous, friction and other types of dampers may be successfully used for this reason (Chang EESDJ 2002) [13]. It is known that buildings with friction dampers don't return to the initial position after the earthquake. In order to overcome this drawback variable friction dampers were recently developed and tested by the authors (Ribakov EEEJ 2006) [14], (Ribakov EEEJ 2006) [15].

A variable friction damper (Fig. 10) consists of a tube (1), a wedge (2), elastic strip elements (3) and a connection clip (4). The wedge may be linear or curved. It can move ahead and back along its axis. The strips are fixed on the tube by the connection clip, forming an elastic strip system. The stiffness of this system may be regulated by changing the location of the connection clip along the tube. The free ends of the cantilever strips have a contact with an inclined surface of the wedge.

The dampers mechanical properties and hysteretic behavior were studied theoretically and verified experimentally using laboratory models (Ribakov EEEJ 2006) [14], (Ribakov EEEJ 2006) [15]. These dampers can be incorporated as a part of a base isolation system in order to yield enhanced structural response and to limit the displacements at the isolators.
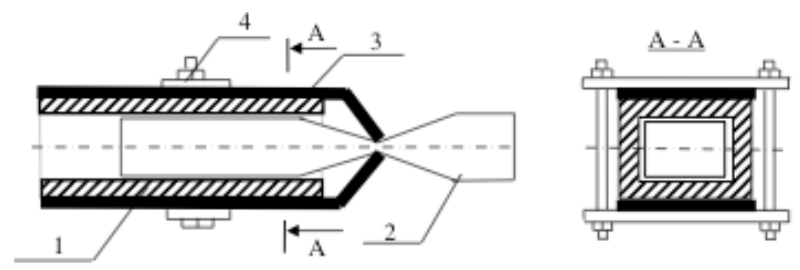

Fig. (10). A scheme of the damper: 1 - square section tube; 2 wedge; 3 - elastic strip elements; 4 - bolted connection clip (Ribakov EEEJ 2006) [14].

\section{CONCLUSIONS}

Base isolation has significant benefits for the earthquake protection of public buildings. It provides high protection level after a strong earthquake by reducing structural seismic response. Thus, base isolation is an acceptable and an effec- 
tive way for protection of such buildings in high seismic activity areas.

Recent earthquakes have shown that base isolated public buildings retrofitted to withstand earthquakes behaved better compared to fixed-base ones. The main advantage of a base isolation system is that no structural elements should be added and that the building should not be closed for the retrofitting period, which is especially important for public buildings.

Design of base isolation systems and selection of their properties usually depend on dynamic characteristics of the isolated building. The last can be obtained by nondestructive impulse testing of the structure before its protection. Alternatively vibration machine testing, micro-seismic blast method or waiting regime procedure may be used.

Rather big displacements at the isolators' level can be reduced by adding supplemental dampers to the base isolation system. Effective variable friction dampers were proposed and tested by the authors. These dampers significantly reduce the displacements between the first floor column and foundation and also yield further improvement in the seismic response of a building.

\section{REFERENCES}

[1] J. M. Kely, Earthquake-Resistant Design with Rubber. 2nd ed. Berlin and New York, Springer-Verlag 1997.

[2] J. M. Kely, "Base Isolation: Origins and Development", EERC News vol. 12 (1), 1991.

[3] A. Mokha, M. C. Constantinou. and A. M. Reinhorn, Teflon Bearings in Base Isolation. Part 1:Testing." Journal of Structural Engineering, ASCE vol. 116 (2), pp. 438-454, 1990.
[4] A. Mokha, M. C. Constantinou, A. M. Reinhorn and Zayas V. "Experimental Study of Friction Pendulum Isolation System", Journal of Structural Engineering, ASCE vol. 117 (4), pp.12031219, 1991.

[5] F. Naeim and J. Kely, Design of seismic isolated structures: from theory to practice. Wiley NY, 1999.

[6] San Francisco City Hall, Internet resource http://www.celebratingeqsafety.com/sf-city-hall

[7] Holmes Consulting Group - Base Isolation, Internet resource http://www.holmesgroup.com/baseisolation.html

[8] S. H. Negmatullaev, M. D. Djabarov and O. V. Sirma, "Full-scale dynamic tests of clay brick buildings using seismic-blast method". International Conference on Modern Aspects in Development of Seismic Resistance and Seismology, Dushanbe 172-178 (in Russian), 2005.

[9] I. Iskhakov, "Calculation and Design of RC Shells for Seismic Regions". Maorif, Dushanbe 1983 (in Russian).

[10] I. Iskhakov and Y. "Ribakov Selecting the properties of a base isolation system based on impulse testing of a three-story structural part", European Earthquake Engineering Journal XIX vol. 1, pp. $38-42,2005$.

[11] I. Iskhakov and Y. Ribakov "Experimental and numerical investigations of a full-scale multistory RC building under dynamic loading". The Structural Design of Tall and Special Buildings Journal vol. 14 (4), pp. 299-313, 2005.

[12] Iskhakov I. Seismic resistant roof constructions made of RC monolithic shell with steel diaphragms. Bulletin of IASS for shell structures 1981.

[13] S. Chang, N. Makris, A. Whittaker and A. "Thompson Experimental and analytical studies on the performance of hybrid isolation systems", Earthquake Engineering and Structural Dynamics Journal vol. 31 pp. 421-443, 2002.

[14] Y. Ribakov, B. Blostotsky and I. Iskhakov, "Theoretical model and laboratory tests of variable friction damper", European Earthquake Engineering vol. 1, pp. $36-42,2006$.

[15] Y. Ribakov, B. Blostotsky and I. Iskhakov, "An efficient variable friction damper with a curved wedge", European Earthquake Engineering vol. 2, pp. $32-38,2006$. 